\title{
The Role of Subtitling and Dubbing in Arabic Vocabulary Acquisition: A Contrastive Study
}

\section{Asil Qasim}

College of Humanities and Social Sciences

Hamad Bin Khalifa University, Qatar

Rashid Yahiaoui

College of Humanities and Social Sciences

Hamad Bin Khalifa University, Qatar

\begin{abstract}
The critical comparison of subtitling and dubbing has long been a subject of discussion by many researchers in the field of Audiovisual Translation. However, to the best of our knowledge, no study to investigate the role of subtitling and dubbing in vocabulary acquisition has been carried out in the Arab world. The aim of the present study is to measure the effect of Audiovisual Translation modalities, mainly subtitling and dubbing, in the acquisition of Arabic vocabulary in an Arabic as a foreign language class (AFL) carried out at Sultan Qaboos College for Teaching Arabic For Non-Native Speakers. In order to do this a couple of questions needed answers 1) Which modality (subtitling and/or dubbing) is more conducive to vocabulary acquisition in the Arabic language? And 2) Which modality is more efficient in the long-term memory retention of Arabic vocabulary? Thirty upper intermediate students participated in this case study, which involved them watching a four-minute clip of the American TV series Designated Survivor in three versions: (a) subtitled into Arabic, (b) dubbed into Arabic, and (c) dubbed and subtitled in Arabic. The results showed that all groups were able to acquire and retain second language (L2) vocabulary; however, the dubbing group achieved higher results in both the immediate post-test and the delayed post-test.
\end{abstract}

Keywords: dubbing, education, language learning, subtitling, vocabulary acquisition

Cites as: Qasim, A., \& Yahiaoui, R.(2019). The Role of Subtitling and Dubbing in Arabic Vocabulary Acquisition: A Contrastive Study. Arab World English Journal for Translation \& Literary Studies, 3 (1) 74-86. DOI: http://dx.doi.org/10.24093/awejtls/vol3no1.6 
AWEJ for Translation \& Literary Studies Volume, 3 Number 1. February 2019

The Role of Subtitling and Dubbing in Arabic Vocabulary

Qasim \& Yahiaoui

\section{Introduction}

Vocabulary is a fundamental tool in language learning which connects individuals, communities, nations and even cultures to each other. Wilkins (1973) highlights the importance of vocabulary in language learning by stating:

There is not much value in being able to produce grammatical sentences if one has not got the vocabulary that is needed to convey what one wishes to say... Without grammar very little can be conveyed, without vocabulary nothing can be conveyed (p. 97)

Wilkins' words underline the vital role vocabulary plays in language teaching and learning, as it is considered the base for the development of other skills such as reading, speaking, listening and writing. Through learning vocabulary, students understand the meaning of a word or string of words; and therefore, increase their ability to communicate with others.

Audiovisual Translation (AVT) is becoming part of everyday life, as it presents one message in different forms and languages; and thus, reaches out to larger audiences from different countries and cultures through different audiovisual products. One easy way to learn languages is through the use of Audiovisual Translation modalities; for example, motion pictures mixed with textual information or with audio in a second or foreign language are considered useful and enjoyable way of learning languages. Naynava and Razavi (2016, p. 3) emphasize that learning vocabulary through multimodal tools differs from books; it affects the cognitive structures and processes as well as the mental representation in the human mind. Therefore, second/foreign language learners are able to build their vocabulary through leisure activities such as watching movies and TV shows.

The aim of the present study is to measure the effect of Audiovisual Translation modalities, mainly subtitling and dubbing, in the acquisition of Arabic vocabulary in an Arabic as a foreign language class (AFL). Therefore, this study hypothesizes that: (1) both Audiovisual modalities (subtitling and dubbing) will result in the acquisition of Arabic vocabulary; and (2) students who watch the subtitled and dubbed clip together (SD-group) will acquire Arabic vocabulary more easily compared to those who watch the subtitled clip (S-group) or the dubbed clip (D-group). Additionally, the study specifically attempts to answer two questions: (1) which modality (subtitling and/or dubbing) is more conducive to vocabulary acquisition in the Arabic language? and (2) which modality is more efficient in the long-term memory retention of Arabic vocabulary?

\section{Audiovisual Translation in the Arab World}

Audiovisual Translation in the Arab world is an emerging field with an increasing number of studies in recent years. Gamal (2015, p. 1) states that research on AVT is relatively new, although subtitling and dubbing have a long history in the Arab world. In fact, AVT was first established in Egypt in 1932, when the first Egyptian silent film Children of The Rich was produced as a "talkie" which combined intertitles and few dialogues (Gamal 2007, p. 79). In the late 1990s, the number of the satellite has increased dramatically in the Arab world and has reached around 100 broadcasting channels. This created a high demand for translators to subtitle foreign programs from English into Arabic to fill the broadcasting hours (Gamal 2007, p. 80). In more recent years, AVT has been used as an educational tool in the study of Second/Foregin Language

Arab World English Journal for Translation \& Literary Studies 
AWEJ for Translation \& Literary Studies Volume, 3 Number 1. February 2019

The Role of Subtitling and Dubbing in Arabic Vocabulary

Qasim \& Yahiaoui

Acquisition. Gamal (2012, p. 822) also emphasizes the importance of AVT in raising education standards in the digital age, noting that digital versatile disks (DVDs) were first used in Eygpt as an educational tool in 1998 in some language centers and for those who could afford home computers. It is worth mentioning that most of the materials shown on DVDs were subtitled, which confirms Gamal's (2007, p. 79) assertion that "subtitling has been the preferred form of audiovisual translation in the Arab world." However, this information is outdated. Arab viewers, nowadays, prefer different AVT modalities depending on the genre.

Dubbing has been carried out for children's cartoons since the 1980s either in Modern Standard Arabic (MSA) or Egyptian dialect, and it is also the preferred option for soap operas. In 1991, the first Mexican soaps were dubbed into MSA, and after a few years, the use of dubbing had significantly increased, especially after the Middle East Broadcasting Corporation (MBC) aired Turkish series dubbed into Syrain, such as Iklil el Ward (The crown of flowers), Sanawat Adaya' (The lost years), Noor (The Light), El 'ishq EI Mamnou' (Forbidden love), Awraq El Mutasaqita (The falling leaves) and many more followed (Yahiaoui 2014, p. 58). A few years later, Korean series and Indian series were also dubbed to MSA or other Arabic dialects. Subtitling, however, remained the preferred modality for English movies, TV shows, and series. The field of AVT in the Arab world is not comprehensive and leaves many areas for further investigation. Until now, as far as our research has shown, no effort to investigate the role of subtitling and dubbing in vocabulary acquisition has been conducted in the Arab world.

\section{Research Background}

Several studies have reported on the positive effects of subtitling on Second Language Acquisition (SLA). Researchers have found that students can improve their listening skills (Başaran \& Köse 2013; Yang 2014; Campbell 2016), reading skills (Koskinen and Wilson; Jensema 1985), and speaking performance (Borras \& Lafayette 1994). Other researchers have considered the use of subtitling activities within the language classroom such as (Koolstra and Beentjes 1999; Perez, Noortgate \& Desmet 2013; Mousavi \& Gholami 2014; Aloqaili 2014). Dubbing, on the other hand, has been utilized, though scarcely, in language learning. Kumai (1996) and Danan (2010) proved the positive effect of dubbing on speaking skills in L2. Moreover, researchers such as Helle (2014), and Matamala, Perego and Bottiroli (2017) took a more holistic approach as they explored the impact of both subtitling and dubbing on different variables, including but not limited to, general comprehension, dialogue recognition, face-name association, visual scene recognition, and vocabulary acquisition in L2. Therefore, this endeavor is not the first to integrate AVT as a pedagogical tool for language learning as several studies have explored the impact of subtitling and dubbing in vocabulary acquisition in other languages. Consequently, it is envisaged that this research is the first step towards a more in-depth analysis regarding this topic in the Arabic context.

\section{Experimental Design}

In this study, we hypothesize that a) both Audiovisual modalities (subtitling and dubbing) will result in the acquisition of Arabic vocabulary, and b) students who watch the subtitled and dubbed clip together (SD-group) will acquire Arabic vocabulary more easily compared to those who watch the subtitled clip (S-group) or the dubbed clip (D-group).

Arab World English Journal for Translation \& Literary Studies 
AWEJ for Translation \& Literary Studies Volume, 3 Number 1. February 2019

The Role of Subtitling and Dubbing in Arabic Vocabulary

Qasim \& Yahiaoui

In order to test our hypotheses, the following questions had to be answered:

1- Which modality (subtitling and/or dubbing) is more conducive to vocabulary acquisition of the Arabic language?

2- Which modality is more efficient in the long-term memory retention of Arabic vocabulary?

\subsection{The Source Text}

Designated Survivor (2016) is an American political drama television series that was broadcasted on ABC channel. The series tells a story of Tom Kirkman, a lower-level cabinet member who is assigned as the President of the United States after the attack on the lives of the president and the Cabinet who are above him in the line of succession. The 4-minute clip was subtitled and dubbed from English into the Arabic Language. The instructor and revised the translation of the video.

\subsection{Participants and Testing Procedure}

The participants in this study were 30 upper intermediate level students from Sultan Qaboos College for Teaching Arabic to Non-Native Speakers, Oman. However, only 23 were considered in this case study. Students were between the ages of 20 and 29, and of three nationalities: Korean, Czech, and Slovak. It is worth mentioning that students' participation was voluntary and for no monetary compensation.

The 30 students were randomly divided into three equal groups of ten participants. At the beginning, students were asked to sign a consent form and to fill out an initial questionnaire regarding their demographic information, preference of modality when watching videos to learn the Arabic language, their learning experience, and motivation for learning the Arabic language. Afterward, students were given a brief explanation of the experiment and were told that a test would be administered after watching the clip.

A pre-vocabulary test was distributed to the students, before watching the clip, to check that the target words were unknown. The pre-vocabulary test consisted of a vocabulary list of 20 Arabic words. Ten words were selected from the clip, which later were tested in the immediate and delayed post-tests. The words were written in a table with three-level measurement scales (I do not know the word; I have seen/heard the word before but I do not know its meaning; and I know the word very well). Additionally, students were asked to define or translate the words they were familiar with. It is worth mentioning that, as per the discussion with the teacher, students had already been exposed to most of the words used in the clip, which mean that they would be able to understand the clip; and thus, would more easily acquire the new vocabulary.

Additionally, the length of the target words was within students' level of acquisition, namely two to three syllables. All students were familiar with three target words out of ten; therefore, they were omitted from the test because the aim of the research was to measure students' acquisition of words that they do not have any prior knowledge of. In addition, the selections of target words were based on the discussion we had with the teacher. He suggested that students at the upper intermediate level have a good amount of concrete vocabulary, which refers to tangible qualities and ideas. Conversely, their knowledge of abstract words is not strong, as they have not 
AWEJ for Translation \& Literary Studies Volume, 3 Number 1. February 2019

The Role of Subtitling and Dubbing in Arabic Vocabulary

Qasim \& Yahiaoui

been sufficiently exposed to these words in their studies. Consequently, the students were tested only on abstract nouns.

Each group of ten participants watched a four-minute clip in a specific modality: (a) subtitled into Arabic (S-group); (b) dubbed into Arabic (D-group); and (c) subtitled and dubbed into Arabic (SD-group). After watching the clip, an immediate post-test was administered including ten words that appeared in the clip. Students were told how to answer the Vocabulary Knowledge Scale (VKS) test and the five-level scale was explained. After two weeks, a delayed post-test including the same items of vocabulary was administered to the students. Additionally, Students' reactions during the viewing of the clip was observed using a minute-log in order to correlate students' reactions when they were watching the clip to their results of the tests. The observation was done covertly in order to allow students to behave naturally. Also, a focus group discussion was carried out with the students after the delayed post-test to provide triangulation for the results of the study. After the experiment was done, a comparison between the pre-vocabulary test, immediate and delayed post-tests was made to examine the impact of subtitling and/or dubbing on the acquisition of the Arabic language for Arabic non-native class.

\subsection{The Vocabulary Knowledge Scale (VKS)}

All tests were modeled in light of the VKS test, which is a five-point self-report scale designed by Wesche and Paribakht (1996). The VKS is a generic instrument, in the sense that it can be used to measure any set of words, and to measure full and partial knowledge of the target words. As Wesche and Paribakht (1996, p. 179) indicate, the test ranges "from complete unfamiliarity, through recognition of the word and some idea of its meaning, to the ability to use the word with grammatical and semantic accuracy in a sentence." As shown in table 1, each answer of the VKS corresponded to a numerical point.

Table 1: The VKS Scoring Categories: Assignment of Scores to Responses

0 Points I don't remember having seen this word before.

1 Point I have seen this word before but I don't know what it means.

2 Points I have seen this word before and I think it means.........(synonym or translation).

3 Points I know this word. It means........(synonym or translation).

4 Points $\quad I$ can use this word in a sentence.

\section{Analysis and Findings}

At the beginning, students were asked about their preference for watching films or videos outside the class context. Figure 1 shows the percentage of students' preference of modality when watching movies to learn the Arabic Language. As shown, 20 students (86.95\%) stated that they prefer watching subtitled videos when learning the Arabic language, while only three students $(13.05 \%)$ reported that they prefer dubbed films to learn L2 vocabulary. 
AWEJ for Translation \& Literary Studies Volume, 3 Number 1. February 2019

The Role of Subtitling and Dubbing in Arabic Vocabulary

Qasim \& Yahiaoui

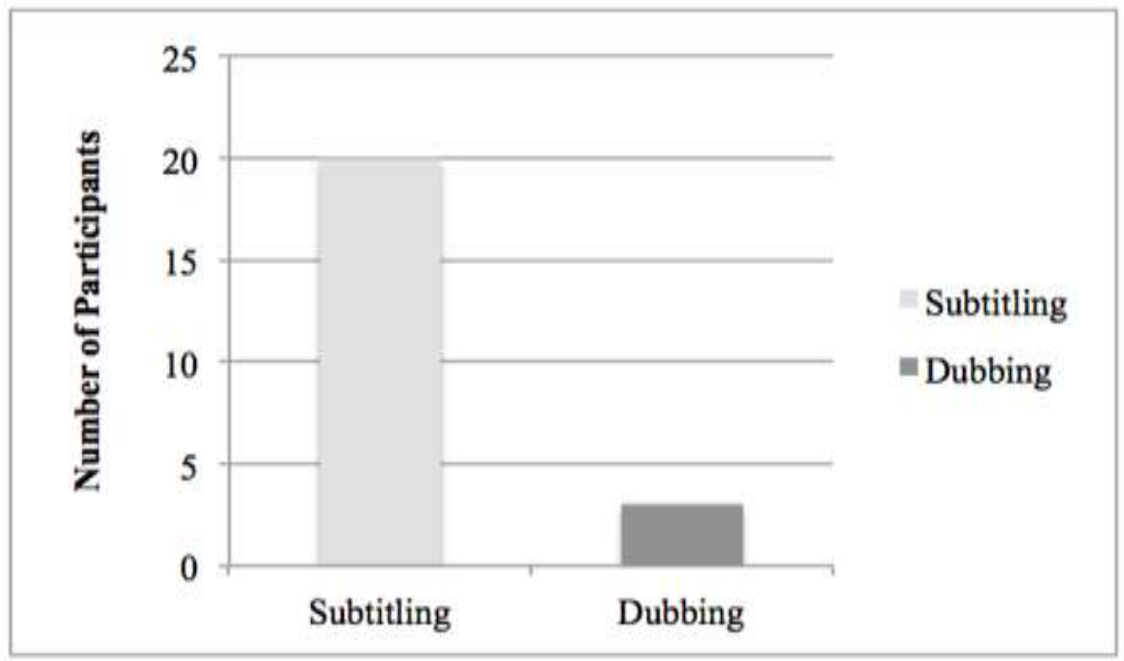

Figure 1: Students' Preference of Modality

The participants of this study belong to dubbing countries: Korea, The Czech Republic, and Slovakia. Although dubbing is usually adopted for television in The Czech Republic and Slovakia, in cinema they have the choice to watch the movie either subtitled or dubbed into their native language (The European Commission Report 2011, p. 6). Likewise, Korean students mentioned that they have the same feature in their country (Personal communication, 2018).

A European Commission report on the potential use of subtitling to encourage foreign language learning and improve the mastery of foreign languages (2011, p. 20) describes how 1515 students who belong to dubbing countries were surveyed regarding their viewing preference (subtitled, dubbed, or original dialogue) for a film in a known foreign language. The study was conducted on members of 33 European countries and took over a year to complete. The results of the report showed that $36 \%$ of the students preferred watching the original clip with no use of AVT modalities, whereas $48.5 \%$ mentioned that they preferred subtitling, and only $15 \%$ preferred dubbing. Although the participants of this study belong to dubbing countries, they chose subtitling as a preferred method of watching clips in L2. However, students of this case study might not be used to this method because they tend to watch dubbed videos on television and mostly in cinema, as in the focus group discussion, 23 students (76.7\%) mentioned that when they go to the cinema they choose to watch the movie dubbed into their language because they cannot keep up with the subtitles. Seven students (23.3\%), on the other hand, usually choose subtitling when watching movies at the cinema. This might suggest that although students prefer watching subtitled clips to learn Arabic, the short duration of the subtitles on screen discourages them from choosing subtitled versions at the cinemas. The results of the European Commission report are in line with students' preference of modality. As was the case with the European Commission report, the participants of this case study belong to dubbing countries, and likewise, the majority $(86.95 \%)$ preferred subtitling over dubbing.

\subsection{Immediate Post-Test Results}

Students' answers to the immediate post-test questions were calculated manually and then were analyzed. Figure 3 illustrates students' scores in the immediate post-test. 
AWEJ for Translation \& Literary Studies Volume, 3 Number 1. February 2019

The Role of Subtitling and Dubbing in Arabic Vocabulary

Qasim \& Yahiaoui

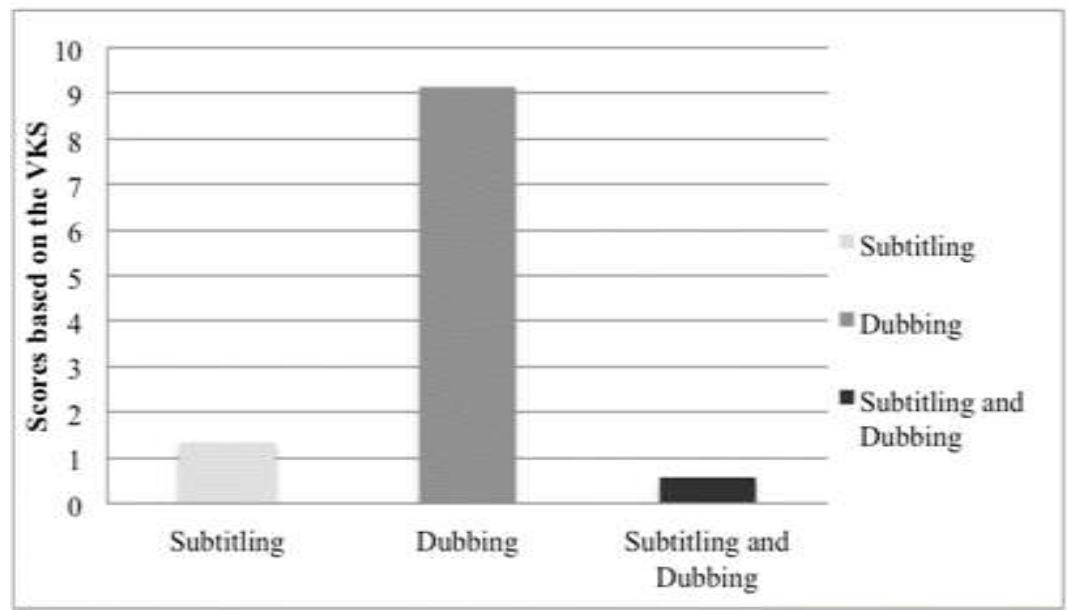

Figure 2: Average Scores of Intermediate Post-Test

All groups demonstrated improvement in vocabulary acquisition in L2. However, the Dgroup obtained better results in the immediate post-test $($ Mean $=9.14)$ than the S-group (Mean = 1.33 ) or the SD-group (Mean $=0.57$ ). After calculating the t-test for the results, it was found that there was a significant difference between D-group and the other two groups, as P-value was 0.006 with S-group and 0.04 with SD-group $(\mathrm{P}<.05)$. The t-test was also calculated for the S-group and SD-groups. It revealed that there was no significant difference in students' answers in the other two conditions as P-value was 0.28 (P>.05). It is therefore clear from this figure that the D-group attained higher scores in the immediate post-test than the other groups. This result refuted our second hypothesis, which suggests that SD-group will achieve higher results in the immediate and delayed post-tests.

\subsection{Delayed Post-Test Results}

After two weeks, a delayed post-test, which was identical to the immediate post-test, was administered to the students. The aim of this test was to measure students' long-term vocabulary retention. Figure 3 shows students' scores in the delayed post-test.

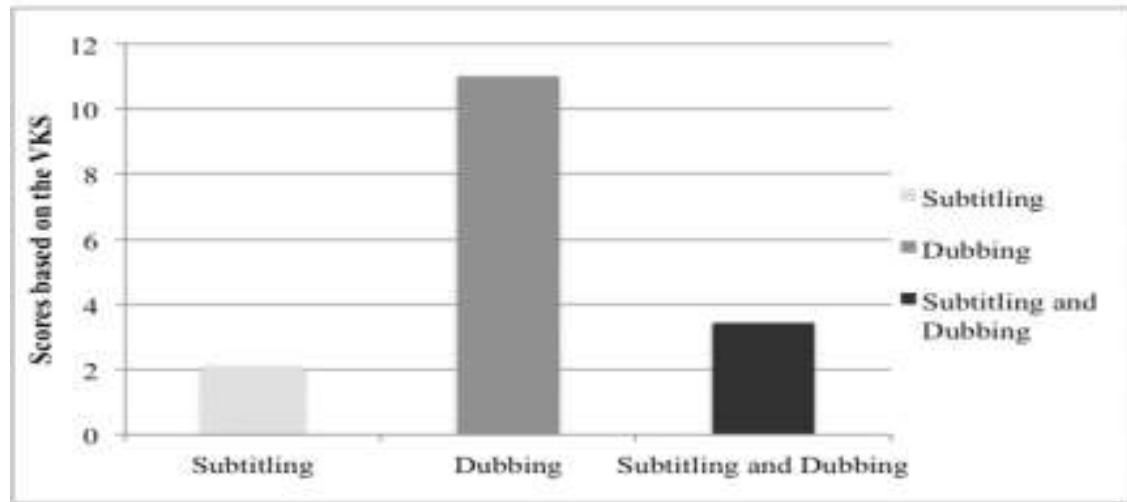

Figure 3: Average Scores of Delayed Post-Test

Arab World English Journal for Translation \& Literary Studies 
Looking at figure three, it is clear that the D-group achieved higher results in the delayed post-test $($ Mean= 11), compared to the SD-group $($ Mean=3.42), and the S-group $($ Mean=2.11). Ttests were also performed in the delayed post-tests to indicate if there was a statistically significant difference between the three modalities. After calculating the t-test, it appeared that there was a significant difference between the D-group compared to the other two groups as P-value was less than 0.05 , namely 0.03 with the SD-group, and 0.01 with the S-group. However, P-value was higher than 0.05 between the S-group and SD-group, namely $(p=0.54)$. While there was no statistically significant difference between the two groups; an improvement in students' performance was found in L2 vocabulary acquisition in the S-group and the SD-group. All groups were able to retain some vocabulary mentioned in the clip. This indicates the general positive effect of subtitling and/or dubbing in SLA. In addition, the results confirm our first hypothesis that both audiovisual modalities (subtitling and dubbing) will result in second language vocabulary acquisition. This proves that AVT modalities can be utilized as a pedagogical tool in the Arabic context.

At the end of the experiment, students were asked in the focus group discussion if they preferred learning L2 through AVT material or through traditional ways. Figure 4 demonstrates their answers regarding their preferences for language learning.

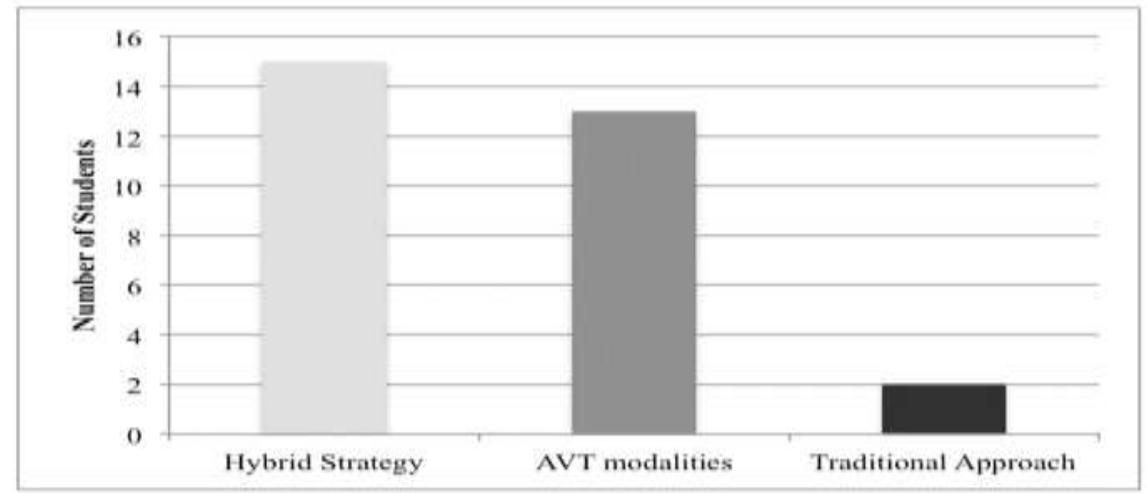

Figure 4: Students' Preferences in Learning L2

Based on figure 4, students' attitude towards subtitling and dubbing as a pedagogical tool was positive. 15 students $(50 \%)$ reported that they prefer a hybrid strategy in learning L2 vocabulary, whereas 13 students (43.4\%) stated that they prefer AVT modalities, mainly subtitling and dubbing, to learn L2, and only two students $(6.6 \%)$ reported that they prefer the traditional approach for learning.

\subsection{Comparison between Immediate and Delayed Post-Test Results}

By comparing students' performances from immediate post-test to delayed post-test, it was found that students' retention of Arabic vocabulary improved in the delayed post-test. Figure 5 illustrates the average score of students' performance in the post-tests (immediate to delayed). 
AWEJ for Translation \& Literary Studies Volume, 3 Number 1. February 2019

The Role of Subtitling and Dubbing in Arabic Vocabulary

Qasim \& Yahiaoui

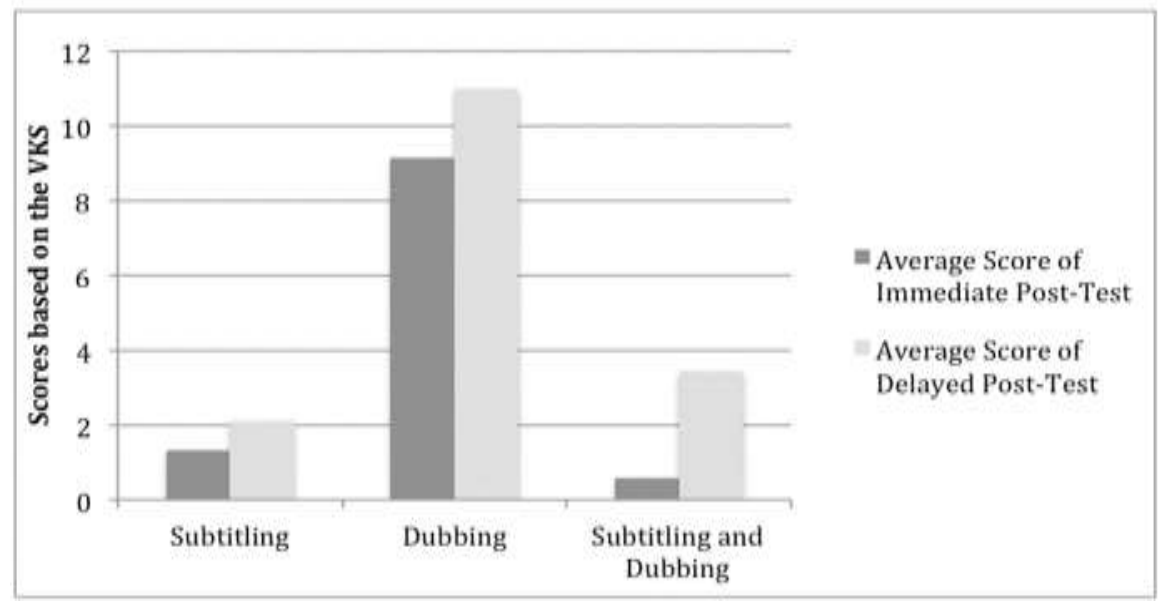

Figure 5: Average Score of Students' Performance in Immediate and Delayed Post-Tests

The improvement in each group was measured through t-test in order to indicate if there was a statistically significant difference in students' performance from the immediate post-tests to delayed post-tests. The t-test revealed that there was no significant difference in students' performance in the post-tests for all modalities as P-value was higher than 0.05 , that is 0.38 with the S-group, 0.57 with the D-group, and 0.2 with the SD-group. In other words, by comparing the three conditions, it can be concluded that the D-group obtained better results in both immediate and delayed post-tests than the S-group and the SD-group. However, there was no significant difference in students' performance from the immediate post-test to delayed post-test in all modalities.

One plausible explanation for the results is that students belong to dubbing countries, which might suggest that they are accustomed to watching dubbed videos more the subtitled ones. As a result, they might have spent more time focusing on reading the subtitles; and therefore, they were unable to process the L2 input. The subtitles might have distracted the students. If so, this would confirm Gottlieb's (1994) and Mera's (1999) claims that subtitles can be considered as a distraction as well as less effective in content comprehension and memory performance due to the multiple linguistic codes, which consist of listening, reading, and visual perception of images. Therefore, subtitling requires high mental effort and workload in order to understand the clip (Koolstra, Peeters \& Spinhof 2002, p. 331). In a more recent study by Perego, Del Missier and Stragà (2018, p. 22), it was argued that "subtitling is associated with more subjective effort than dubbing which leads to lower comprehension and lower memory." This corresponds with the results of this study as the S-group and the SD-group obtained lower results in the immediate and delayed post-tests. Although subtitles are considered as a visual aid based on previous studies (Koolstra \& Beentjes 1999; Bravo 2008; Lertola 2012; Perez, Noortgate, \& Desmet 2013; Mousavi \& Gholami 2014), it appears that they might have also distracted students and thus hampered the acquisition of L2 vocabulary in this particular case study.

Sydorenko (2010, p. 1) argues "learners usually pay most attention firstly to subtitles, then to images, and lastly to audio." As a result, students might have paid too much attention to reading the Arabic subtitles, and not enough to watching the images and/or listening to the audio. 
AWEJ for Translation \& Literary Studies Volume, 3 Number 1. February 2019

The Role of Subtitling and Dubbing in Arabic Vocabulary

Qasim \& Yahiaoui

Consequently, they could not correlate the target words with the original audio. As a result, Sgroup and SD-group did not achieve high scores in the post-tests. On the other hand, D-group achieved higher results in both immediate and delayed post-tests.

Perego, Del Missier, and Bottiroli (2018, p. 21) suggests that dubbing is considered more beneficial than subtitling when viewers are not familiar with subtitling especially for complex AV materials. This view might be pertinent in this case, especially that participants are slow readers of Arabic subtitles as they are in the intermediate level and the Arabic language is not their first language (L1). During the focus group discussion, students were asked how often they watched subtitled videos outside the classroom. All students answered that they watch subtitled videos in the Arabic language outside the classroom in order to learn new Arabic vocabulary. However, they mentioned that they usually needed to slow down the video in order to be able to read the subtitles fully. In addition, they also tend to pause the video while watching to be able to write down the new vocabulary. Therefore, this might suggest that students watched subtitled videos outside the classroom, as they have the freedom to slow down, pause and repeat the video. However, they are not accustomed to reading subtitling in Arabic in a classroom setting, as the subtitles have to appear on the screen for a limited time, and students have no option to slow down or pause the video. Familiarity and practice are likely to increase the speed at which Arabic subtitles are processed and thus reduce the amount of time needed to read the subtitles fully.

The complexity of the Arabic alphabet might be one of the reasons for the S-group and SD-group not obtaining high scores in the immediate and delayed post-tests. Arabic orthography differs from other languages in several ways. For example, the letters are connected with former and/or subsequent letters, and they have different shapes depending on the positional variant of the letter itself. This might suggest that the "visual complexity of Arabic letters results in an increased processing load, thus slowing performance in Arabic" (Ibrahim, Eviatar \& AharonPeretz 2002, p. 325). In other words, the orthographic complexity of Arabic might have had an impact on the participants of this study, as the S-group and the SD-group might have taken longer to decode the visual orthography of the Arabic subtitles. Thus, this resulted in a high mental effort, especially that participants of this case study were non-native speakers of the Arabic language. As a result, this might have affected their performance in the immediate and delayed post-tests.

Another factor that might have influenced the result is the language proficiency of the students, as well as L2 exposure. Some students might have understood more words in the clip and the test than others due to language proficiency in the target language or because they had been exposed to L2 more than others. Although students were all classified as upper intermediate students, some of them were exposed to the Arabic language for more than six years, while others had been learning the language for only a year. Therefore, some of them might have performed better in the post-tests. Moreover, students' personality might have also contributed to the acquisition of Arabic; however, it is difficult to evaluate the impact of these factors on the posttests, as all students showed an improvement in L2 vocabulary, though not significantly.

Interestingly, learners' scores in the delayed post-test were higher than their scores in the immediate post-test. Students are usually accustomed to a certain approach to learning Arabic vocabulary, namely the traditional approach that does not utilize AVT modalities. Therefore, the 
AWEJ for Translation \& Literary Studies Volume, 3 Number 1. February 2019

The Role of Subtitling and Dubbing in Arabic Vocabulary

Qasim \& Yahiaoui

variation of video material might have helped students to engage more parts of the brain to make learning L2 more stimulating. In other words, subtitling and dubbing might have reinforced the target words in students' minds; and accordingly, they were able to increase the retention of L2 vocabulary in the delayed post-test.

\title{
6. Concluding Remarks
}

The educational implications of this case study may be applicable for language classroom contexts in the Arab world. AVT modalities aid the teaching and learning processes by making them more interactive; thus, fostering a collaborative learning environment in which students' interaction increases, and they are more likely to find the given tasks entertaining. Thus, students will learn L2 vocabulary faster with less effort. More specifically, the effective use of AVT improves the learning environment in a classroom as it motivates students, facilitates language skills, and creates innovative learning opportunities for students. Curriculum designers and material development specialists should consider employing Audiovisual Translation modalities as a fundamental tool in instructional material in language teaching.

One of the limitations of this study is that although students of this study are classified as upper intermediate learners of Arabic language, as they all completed the same amount of hours and took a placement test in order to be able to enroll in the course, they differ in their nationality, level of language exposure, life experience, and reading skills. As a result, these characteristics might have affected their ability to acquire and retain the vocabulary tested in this study. In addition, the limited number of participants in each group might be one reason for not proving any statistically significant difference in students' vocabulary improvement from immediate post-test to delayed post-test.

Future studies on the same topic using a larger sample of participants from different age groups, nationalities, and different level of L2 with an increased number of items in the vocabulary test, could yield more comprehensive results regarding the role of subtitling and dubbing in the acquisition of Arabic vocabulary.

\begin{abstract}
About the Authors
Asil Qasim is an MA graduate in Audiovisual Translation program at the translation and Interpreting Institute (TII), Hamed Bin Khalifa University. Before enrolling as a student at TII, Asil pursued a BA in English Linguistics and Translation from Qatar University. Her research interests are Audiovisual Translation, Language Learning, Discourse Analysis, and Media Studies.

Rashid Yahiaoui is currently an Assistant Professor at the College of Humanities and Social Sciences of Hamad Bin Khalifa University, Qatar. He has a Ph.D. in Translation Studies from London Metropolitan University, UK, and a Master in Translation and Interpreting from the University of Salford, UK. Rashid's main research interests are: Audiovisual Translation, Ideology, Critical Discourse Analysis and Media Texts; Political Discourse Analysis, and Translation Pedagogy and Curriculum Development.

https://orcid.org/0000-0002-2523-3113
\end{abstract}

Arab World English Journal for Translation \& Literary Studies 
AWEJ for Translation \& Literary Studies Volume, 3 Number 1. February 2019

The Role of Subtitling and Dubbing in Arabic Vocabulary

Qasim \& Yahiaoui

\section{References}

Aloqaili, G. (2014). Learning Vocabulary from Subtitled Videos: An investigation into The Effectiveness of Using Subtitled Videos for Intentional Vocabulary Learning in Saudi Arabia with an Exploration of Learners' Perspective. Master's thesis, University of Southampton.

Başaran, H., \& Köse, G. (2013). The Effects of Captioning on EFL Learners' Listening Comprehension, Procedia - Social and Behavioral Sciences 70(1), 702-208. http://dx.doi.org/10.1016/j.sbspro.2013.01.112

Borras, I., \& Lafayette, R. (1994). Effects of Multimedia Courseware Subtitling on the Speaking Performance of College Students of French, The Modern Language Journal 78(1), 61-75. http://dx.doi.org/10.2307/329253

Campbell, A. (2016). Subtitling for Mission Accomplishment: An Experimental Study of the Effect of Subtitling as a Task on Listening Comprehension for Learners of Military English for Specific Purposes. Master's thesis, Pablo de Olavide University.

Danan, M. (2004). Captioning and Subtitling: Undervalued Language Learning Strategies, Meta:Translators' Journal, 49(1), 67-77. http://dx.doi.org/10.7202/009021ar.

Danan, M. (2010). Dubbing Projects for the Language Learner: A Framework for Integrating Audiovisual Translation into Task-Based Instruction, Computer Assisted Language Learning 23(5), 441-456. http://dx.doi.org/10.7202/009021ar

Gamal, M. (2007). Audiovisual Translation in the Arab World: A Changing Scene, Translation Watch Quarterly 3(2), 79-80. https://www.researchgate.net/publication/263846928

Gamal, M. (2012). Audiovisual Translation as an Educational Tool in New Egypt. Paper presented at The Asian Conference on Education and Official Conference Proceedings. Osaka, April, 25-28.

Gamal, M. (2015). Omar's Eleven: Challenging Scenes in Subtitling Egyptian Films, Translation Journal 18(1), 1-3. http://translationjournal.net/January-2015/omars-eleven- challenges-in-subtitling-classic-egyptian-films.html

Gottlieb, H. (1994). Subtitling: People Translating People. In C. Dollerup \& A. Lindegaard (Eds.) Teaching Translation and Interpreting 2, 267-280. Amsterdam: John Benjamins.

Helle, M. (2014). The Influence of the Subtitled Mode on the Acquisition of English Vocabulary. Master's Thesis: University of Bergensis.

Ibrahim, R., Eviatar, Z., \& Aharon-Peretz, J. (2002). The Characteristics of Arabic Orthography Slow Its Processing. The American Psychological Association, 16(3), 322326. http://dx.doi.org/10.1037//0894-4105.16.3.322.

Koolstra, C., \& Beentjes, J. (1999). Children's Vocabulary Acquisition in a Foreign Language through Watching Subtitled Television Programs at Home. Educational Technology Research and Development, 47(1), 51-60. http://dx.doi.org/10.2307/30220229.

Koolstra, C., Peeters, A., \& Spinhof, H. (2002). The Pros and Cons of Dubbing and Subtitling. European Journal of Communication 17(3), 325- 354. http://www.sub2learn.ie/downloads/subtitling_pros_and_cons.pdf

Koskinen, P., Wilson, R., \& Jensema, C. (1985). Closed-Captioned Television: A New Tool for Reading Instruction. Reading World, 24(4), 1-7. http://dx.doi.org/10.1080/19388078509557842.

Kumai, W. (1996). Karaoke Movies: Dubbing Movies for Pronunciation. Japan 
AWEJ for Translation \& Literary Studies Volume, 3 Number 1. February 2019

The Role of Subtitling and Dubbing in Arabic Vocabulary

Qasim \& Yahiaoui

Association for Language Teaching, 20, 1-3. http://jalt-publications.org

Matamala, A., Perego, E., \& Bottiroli, S. (2017). Dubbing Versus Subtitling yet Again?:

An Empirical Study on User Comprehension and Preferences in Spain. Babel 63(3), 423441. http://dx.doi.org/10.1075/babel.63.3.07mat.

Mera, M. (1999). Read My Lips: Re-Evaluating Subtitling and Dubbing in Europe. Links \& Letters, 73-85. https://ddd.uab.cat/pub/lal/11337397n6/11337397n6p73.pdf

Mousavi, F., \& Gholami, J. (2014). Effects of Watching Flash Stories with or Without Subtitle and Reading Subtitles on Incidental Vocabulary Acquisition. Procedia-Social and Behavioral Sciences, 98, 1273-1281. http://dx.doi.org/10.1016/j.sbspro.2014.03.543.

Naynava, S. \& Razavi, Z. (2016). An Investigation of the Role of Dubbing, Subtitling and Watching Films on Learning English Language. Paper presented at International Conference on Literature and Linguistics. Iran, December, 2.

Perego, E., Del Missier, F., \& Bottiroli, S. (2015) Dubbing versus Subtitling in Young and Older adults: Cognitive and Evaluative Aspects, Perspectives. Studies in Translatology, 23(1), 1-21. http://dx.doi.org/10.1080/0907676X.2014.912343.

Perez, M., .Van Noortgate, W., \& Desmet, P. (2013). Captioned Video for L2 Listening and Vocabulary Learning: A Meta-Analysis. Elsevier, 41(3), 720-739. http://dx.doi.org/10.1016/j.system.2013.07.013

Sydorenko, T. (2010). Modality of Input and Vocabulary Acquisition. Language Learning \& Technology, 14(2). 50-73. http://llt.msu.edu/vol14num2/sydorenko.pdf

The European Commission. (2011). Study on The Use of Subtitling: The Potential of Subtitling to Encourage Foreign Language Learning and Improve The Mastery of Foreign Languages. Paris: DG Éducation Et Culture.

Wesche, M., \& Sima P. (1996). Vocabulary Enhancement Activities and Reading for Meaning in Second Language Vocabulary Acquisition. In J. Coady and T. Huckin (Eds.), Second Language Vocabulary Acquisition: A Rationale for Pedagogy (pp. 174200). Cambridge: Cambridge University Press.

Wilkins, D. (1973). Review of Linguistics in Language Teaching. The Modern Language Review, 3, 97-99. http://dx.doi.org/10.2307/3725001.

Yahiaoui, R. (2014). Ideological and Cultural Constraints in Audiovisual Translation: Dubbing The Simpsons Into Arabic. PhD diss., Metropolitan University.

Yang, H.Y. (2014). The Effects of Advance Organizers and Subtitles on EFL Learners' Listening Comprehension Skills. CALICO Journal, 31, 345-373. http://www.jstor.org/stable/calicojournal.31.3.345.

Arab World English Journal for Translation \& Literary Studies 